\title{
Modification of palm kernel oil esters nanoemulsions with hydrocolloid gum for enhanced topical delivery of ibuprofen
}

This article was published in the following Dove Press journal:

International Journal of Nanomedicine

4 September 2012

Number of times this article has been viewed

\author{
Norazlinaliza Salim' \\ Mahiran Basri, \\ Mohd BA Rahman' \\ Dzulkefly K Abdullah' \\ Hamidon Basri ${ }^{3}$ \\ 'Department of Chemistry, Faculty of \\ Science, ${ }^{2}$ Laboratory of Biomolecular \\ Medicine, Institute of Bioscience, \\ ${ }^{3}$ Department of Medicine, Faculty \\ of Medicine and Health Sciences, \\ Universiti Putra Malaysia, \\ Selangor, Malaysia
}

\begin{abstract}
Introduction: During recent years, there has been growing interest in the use of nanoemulsion as a drug-carrier system for topical delivery. A nanoemulsion is a transparent mixture of oil, surfactant and water with a very low viscosity, usually the product of its high water content. The present study investigated the modification of nanoemulsions with different hydrocolloid gums, to enhanced drug delivery of ibuprofen. The in vitro characterization of the initial and modified nanoemulsions was also studied.
\end{abstract}

Methods: A palm kernel oil esters nanoemulsion was modified with different hydrocolloid gums for the topical delivery of ibuprofen. Three different hydrocolloids (gellan gum, xanthan gum, and carrageenan) were selected for use. Ternary phase diagrams were constructed using palm kernel oil esters as the oil, Tween 80 as the surfactant, and water. Nanoemulsions were prepared by phase inversion composition, and were gradually mixed with the freshly prepared hydrocolloids. The initial nanoemulsion and modified nanoemulsions were characterized. The abilities of the nanoemulsions to deliver ibuprofen were assessed in vitro, using a Franz diffusion cell fitted with rat skin.

Results: No significant changes were observed in droplet size $(\sim 16-20 \mathrm{~nm})$ but a significant difference in polydispersity indexes were observed before and after the modification of nanoemulsions using gellan gum, carrageenan, and xanthan gum. The zeta potentials of the initial nanoemulsions $(-11.0 \mathrm{mV}$ ) increased to $-19.6 \mathrm{mV},-13.9 \mathrm{mV}$, and $-41.9 \mathrm{mV}$, respectively. The abilities of both the initial nanoemulsion (T802) and the modified nanoemulsion to deliver ibuprofen through the skin were evaluated in vitro, using Franz diffusion cells fitted with rat skin. The in vitro permeation data showed that the modified nanoemulsion (Kp value of $\left.55.4 \times 10^{-3} \mathrm{~cm} \cdot \mathrm{h}^{-1}\right)$ increased the permeability of ibuprofen 4.40 times over T802 (Kp value of $\left.12.6 \times 10^{-3} \mathrm{~cm} \cdot \mathrm{h}^{-1}\right)(P<0.05)$.

Conclusion: The modified nanoemulsion may be a promising vehicle to enhance the permeation of ibuprofen for topical delivery.

Keywords: ibuprofen, in vitro study, palm kernel oil esters, topical delivery

\section{Introduction}

Nanoemulsions are isotropic, transparent (or translucent) systems consisting of oil, surfactant, and water having a droplet size of less than $100 \mathrm{~nm} .{ }^{1}$ Low viscosity, high kinetic stability against creaming or sedimentation, and large interfacial area make nanoemulsions of increasing use in different applications. ${ }^{2}$ In the pharmaceutical field, nanoemulsions have been increasingly developed for use as drug-delivery systems for parenteral, oral, ocular, and topical administration..$^{3-6}$

Specifically, in the case of topical delivery, nanoemulsions offer several significant advantages including no skin irritation, powerful permeation ability, and high
Correspondence: Mahiran Basri Department of Chemistry, Faculty of Science, Universiti Putra Malaysia, 43400 UPM Serdang, Selangor, Malaysia

Tel +603894 67266

Fax +60389466997

Email mahiran@science.upm.edu.my 
drug-loading capacity. ${ }^{7,8}$ However, the low viscosity of nanoemulsion limits their application in topical delivery. Several hydrocolloids, such as xanthan gum, carrageenan, and carbomer 940, have been used to increase the viscosity of nanoemulsions, rendering them more suitable for topical application, when compared with initial nanoemulsions as a vehicle for drug delivery. ${ }^{9}$

Ibuprofen, a nonsteroidal anti-inflammatory drug is very effective for the systemic treatment of rheumatoid arthritis, osteoarthritis, and ankylosing spondylitis. Ibuprofen has been formulated into many topical preparations in order to reduce adverse side effects associated with the hepatic firstpass metabolism. However it is difficult to maintain effective concentrations by topical delivery of ibuprofen due to its poor skin permeation ability. ${ }^{10}$ In order to enhance the permeation of ibuprofen, many formulations such as emulsions and gels, have been explored. ${ }^{11,12}$ There has been little study of the use of nanoemulsion as a delivery system for ibuprofen.

Palm kernel oil ester (PKOE) is a long chain fatty acid synthesized from palm kernel oil, through the enzymatic process of transesterification. PKOE is rich in oleyl laurate, C30:1 (54.1\%), ${ }^{13}$ and it can be used as an oil phase due to its unique property of exhibiting excellent wetting behaviour without the oily feeling. ${ }^{14,15}$ PKOE has low viscosity and is colorless (which are desirable properties in cosmetic and pharmaceutical products). Until now, there has been little attempt to prepare nanoemulsions using PKOE. In the present study, an initial nanoemulsion (T802) was prepared containing $2 \%$ ibuprofen incorporated in PKOE, and was then modified with different hydrocolloids. The physicochemical properties of each nanoemulsion were characterized and compared. In vitro drug permeations of ibuprofen from initial and modified nanoemulsions through excised rat skin, were also evaluated.

\section{Material and methods Materials}

PKOE was prepared in the laboratory according to the method of Gunawan et $\mathrm{al}^{15}$ and purified with methanol (1:1). ${ }^{14}$ The fatty acids composition of PKOE is: $0.5 \%$ oleyl caproate (C24:1), 5.6\% oleyl caprate (C26:1), 5.9\% oleyl caprylate (C28:1), 54.1\% oleyl laurate (C30:1), 13.9\% oleyl myristate (C32:1), 6.2\% oleyl palmitate (C34:1), $1.2 \%$ oleyl stearate $(\mathrm{C} 36: 1), 6.4 \%$ oleyl oleate $(\mathrm{C} 36: 2)$ and 1.7\% oleyl linoleate (C36:3). Ibuprofen [2-(4-isobutylphenyl)propionic acid] was purchased from Eurochem (Moscow, Russia). The nonionic surfactant Tween 80 (polyoxyethylene sorbitan monooleate) was purchased from Merck (Merck
KGaA, Darmstadt, Germany). Gellan gum was purchased from CPKelco (Atlanta, GA). Xanthan gum and carrageenan were purchased from Merck. Water was deionized and Milli-Q (Millipore, Billerica, MA) filtered in our laboratory.

\section{Methods}

\section{Construction of ternary phase diagram}

The mixture of PKOE and Tween 80 were weighed at various weight ratios ranging from 0:100-40:60. Five mixtures were prepared. Each mixture, with a total weight of $0.5 \mathrm{~g}$, was placed into a $10 \mathrm{~mL}$ screw-cap glass tube (total five tubes), and was vortexed using a vortex mixer (VM-300; Gemmy Industrial Corporation, Taipei, Taiwan). Water (5 wt \%) was then added and the samples were vortexed for 5 minutes. The samples were then centrifuged at $4000 \mathrm{rpm}$ for 15 minutes and observed using polarized light. The steps were repeated with the stepwise addition of $10 \mathrm{wt} \%, 20 \mathrm{wt} \%, 30 \mathrm{wt} \%$, $40 \mathrm{wt} \%$, until $90 \mathrm{wt} \%$ of water. Ternary phase diagrams were constructed by using the Chemix School v3.50 software (Arne Standnes, Norway).

\section{Preparation of nanoemulsion containing ibuprofen}

A composition from the phase diagram was chosen and ibuprofen was added with composition shown in Table 1. Nanoemulsions were prepared at 20:80 of oil-surfactant ratio by the stepwise addition of water into the oil phase, as described in a previously developed method (manuscript under review). The samples were homogenized by a vibromixer (Gemmy Industrial Corporation). All the samples were kept at room temperature, $25^{\circ} \mathrm{C} \pm 2{ }^{\circ} \mathrm{C}$.

\section{Modification of PKOE nanoemulsion}

Gellan gum, carrageenan, and xanthan gum were used to modify the PKOE- nanoemulsion formulations. These hydrocolloids were hydrated in a fixed amount of water for at least 4 hours, and the previously formulated nanoemulsion was gradually added with continuous stirring. After the hydrocolloid was entirely dissolved in the nanoemulsion, clear PKOE nanoemulsions were obtained. The composition of the modified nanoemulsion is described in Table 2.

Table I Composition of the nanoemulsion formulation

\begin{tabular}{lllll}
\hline Code & \multicolumn{4}{l}{ Ingredient $(\%$ w/w) } \\
\cline { 2 - 5 } & PKOE & Tween $\mathbf{8 0}$ & Ibuprofen & Water \\
\hline T802 & 3.6 & 14.4 & 2 & 80 \\
\hline
\end{tabular}

Note: Code T802 represents the surfactant Tween 80 with number 2 (20:80 of oil/ surfactant ratio).

Abbreviation: PKOE, palm kernel oil esters. 


\section{Droplet size and polydispersity analysis}

The mean droplet size and polydispersity of the nanoemulsions and modified nanoemulsions were measured by dynamic light scattering. The measurements were conducted with the zetasizer (Nano ZS; Malvern Instruments Ltd, Malvern, UK). The mean hydrodynamic diameter (z-average mean) was calculated from the autocorrelation function of the intensity of light scattered from the particles. The software used was DTS Nano version 5.03, supplied by the manufacturer (Malvern Instruments Ltd). All the samples were diluted with water prior to measurement. Polydispersity indexes lower than 0.2 are ideal, as they indicate a narrow range of size distribution.

\section{Zeta potential analysis}

The rate of particle movement under the influence of an external oscillating electrical field with a voltage of $150 \mathrm{~V}$ (electrophoretic mobility) was measured with the zetasizer (Malvern Instruments Ltd). The measured electrophoretic mobilities were converted to zeta potentials by the instrument's software (Dispersion Technology Software, version 5.03; Malvern Instruments Ltd) using Henry's equation:

$$
U_{e}=\frac{2 \varepsilon \zeta f(\kappa \alpha)}{3 \eta}
$$

where $U_{e}$ is the electrophoretic mobility, $\varepsilon$ is the dielectric constant, $\zeta$ is the zeta potential, $\eta$ is the viscosity of the dispersant, and $f(\kappa \alpha)$ is the Henry function. The Smoluchowski approximation, $f(\kappa \alpha)=1.5$, was used for high ionic strength media and the Debye-Hückel approximation, $f(\kappa \alpha)=1$, was used for low dielectric medium.

\section{Rheological measurement}

The rheology of the selected nanoemulsion was determined using the Kinexus Rotational Rheometer (Malvern Instruments Ltd). A stress/rate with a temperature controller was employed to measure the rheological properties of the emulsions. The measurements were performed at a temperature of $25.0^{\circ} \mathrm{C} \pm 0.5^{\circ} \mathrm{C}$ with a $4^{\circ} / 40 \mathrm{~mm}$ cone and

Table 2 Composition of the modified nanoemulsion formulations

\begin{tabular}{|c|c|c|c|c|c|}
\hline \multirow[t]{2}{*}{ Code } & \multicolumn{5}{|l|}{ Ingredient (g) } \\
\hline & Nanoemulsions & GG & CG & $\mathbf{X G}$ & Water \\
\hline$\overline{M I}$ & 40 & 0.75 & - & - & 49.25 \\
\hline M2 & 40 & - & 0.75 & - & 49.25 \\
\hline M3 & 40 & - & - & 0.75 & 49.25 \\
\hline
\end{tabular}

Abbreviations: GG, gellan gum; CG, carrageenan; XG, xanthan gum; M, modified nanoemulsion. plate geometry and gap of $0.100 \mathrm{~mm}$. The steady rheological behavior of the emulsions was measured at a controlled rate varying from $0.1-100 \mathrm{~s}^{-1}$. After being loaded onto the plate, the samples were allowed to rest for 10 minutes prior to measurement.

\section{TEM analysis}

The morphology of the particles in the nanoemulsion formulations was visualized with a transmission electron microscope (TEM). Samples were dropped onto a 200 mesh formvar carbon-coated copper grid (Polyscience, Inc, Pennsylvania, PA) and were negatively stained with $50 \mu \mathrm{L}$ of $2 \mathrm{wt} \%$ phosphotungstic acid for 5 minutes, at room temperature. Excess liquid was removed with a piece of Whatman filter paper No. 1 (Whatman International Ltd, Kent, UK), and the samples were dried at room temperature. The samples were observed with TEM (H-7100; Hitachi Ltd, Tokyo, Japan). The acquired digital images were processed with Adobe Photoshop ${ }^{\circledR}$ software (Adobe, San Jose, CA).

\section{In vitro permeation studies}

\section{Preparation of the skin}

Abdominal skins from male Wistar rats weighing 200-300 g were used in this study. All experimental procedures were performed in accordance with the Guidelines of the Animal Ethical Committee of Universiti Sains Malaysia, and had its approval. Rats were anesthetized using sodium pentobarbital administered by intraperitoneal injection. The abdominal skin was shaved using electric and hand razors, and surgically removed. The adherent subcutaneous fat was carefully cleaned. In order to remove the extraneous debris and leachable enzymes, the skin was immersed in a normal saline solution $(0.9 \% \mathrm{NaCl})$ for 1 hour, and then the skin was rinsed with fresh saline solution. This step was repeated 3-4 times. The cleaned skin was wrapped in aluminum foil and stored in a deep freezer at $-21^{\circ} \mathrm{C}$ until further use. Following skin excision, rats were euthanized using an overdose of pentobarbital.

\section{The permeation studies}

The experiment was performed by using Franz diffusion cells with an effective diffusion area of $0.64 \mathrm{~cm}^{2}$. The excised skin samples were clamped between the donor and the receptor chamber of Franz diffusion cells, with the stratum corneum facing the donor chamber. Then, $0.1 \mathrm{~mL}(\mathrm{Co}=20 \mathrm{mg} / \mathrm{mL})$ of the sample was administrated on the stratum corneum. The receptor compartment was filled with a phosphate buffer with a $\mathrm{pH}$ of 7.4 , and maintained at a constant temperature 
of $37^{\circ} \mathrm{C} \pm 0.5^{\circ} \mathrm{C}$ by a circulating-water jacket and constant magnetic stirring. Samples were periodically drawn (typically at 1, 2, 3, 4, 5, 6, 7 and 8 hours) from the receptor compartment and replaced with the same volume of receptor medium. All samples were analyzed by ultra-performance liquid chromatography (UPLC).

\section{UPLC analysis}

UPLC was performed using Waters Acquity UltraPerformance Liquid Chromatographic system (Waters Corporation, Milford, MA) equipped with a TUV detector, an autosampler and a binary solvent delivery system. Data was collected and processed by the chromatographic software Empower 2 Software (Waters Corporation). An Acquity UPLC BEH C18 $(2.1 \mathrm{~mm} \times 50 \mathrm{~mm}, 1.7 \mu \mathrm{m})$ was used as a stationary phase. The mobile phase consisting of a mixture of Acetonitrile/water (55:45 ratio, $1 \mathrm{~L}$ ), potassium dihydrate phosphate $\left(\mathrm{KH}_{2} \mathrm{PO}_{4}, 2.758 \mathrm{~g}\right)$ and orthophosphoric acid $\left(\mathrm{H}_{3} \mathrm{PO}_{4}, 4.7 \mathrm{~mL}\right)$ was used. The detection wavelength was $264 \mathrm{~nm}$ and the run time was 4 minutes. UPLC utilized flow rates in a range of $0.4 \mathrm{~mL} / \mathrm{min}$. All analyses were performed at $25^{\circ} \mathrm{C}$. An injection volume of $10 \mu \mathrm{L}$ with a partial loop mode for the sample injection was used. Ibuprofen stock solution of $1000 \mu \mathrm{g} / \mathrm{mL}$ was prepared by dissolving appropriate weight of ibuprofen in phosphate buffer, $\mathrm{pH} 7.4$ for calibration. Then the stock solution was serially diluted to produce concentrations of $500,300,100,50,10$ and $5 \mu \mathrm{g} / \mathrm{mL}$.

\section{Permeation rate}

The cumulative amount of ibuprofen permeated through rat skin was plotted as a function of time. The permeation rates of ibuprofen at a steady-state $\left(\mathrm{J}, \mu \mathrm{g} \cdot \mathrm{cm}^{-2} \cdot \mathrm{h}^{-1}\right)$ were calculated from the slope of the linear portion of the cumulative amount permeated per unit area versus time plot.

\section{Permeability coefficient $\left(\mathrm{K}_{\mathrm{p}}\right)$}

Permeability coefficient $\left(\mathrm{K}_{\mathrm{p}}\right)$ was calculated from the following equation:

$$
\mathrm{K}_{\mathrm{p}}=\frac{\mathrm{J}}{\mathrm{C}_{0}}
$$

where $\mathrm{J}$ was the skin permeation rate and $\mathrm{C}_{0}$ was the concentration of drug at the donor compartment.

\section{Statistical analysis}

Data was shown as mean \pm SD $(n=3)$. Statistical data was analyzed by using a $t$-test and analysis of variance (ANOVA). $P<0.05$ was considered statistically significant.

\section{Results and discussion Ternary phase diagram of PKOE/ Tween 80/water system}

Figure 1 shows the ternary phase diagram of the PKOE/ Tween $80 /$ water system at $25^{\circ} \mathrm{C}$. The phases observed were: Isotropic liquid phase $\left(\mathrm{L}_{1}\right)$, liquid crystalline phase $\left(\mathrm{L}_{\mathrm{c}}\right)$ and multiphase region. The formation of two $\mathrm{L}_{1}$ regions were found to be towards the water rich-apex and surfactantrich apex of the diagram. A large $\mathrm{L}_{\mathrm{c}}$ region was found in between these two $\mathrm{L}_{1}$ regions. The maximum amount of oil that could be solubilized in the $\mathrm{L}_{\mathrm{c}}$ region was $20 \mathrm{wt} \%$ with $45 \mathrm{wt} \%-75 \mathrm{wt} \%$ of Tween 80 . It has previously been reported that the main factor for the formation of nanoemulsion was the presence of an $\mathrm{L}_{\mathrm{c}}$ region along the emulsification path. ${ }^{16}$ Therefore, the system in which surfactant was at low concentration (lower than $20 \mathrm{wt} \%$ ) in the $\mathrm{L}_{1}$ region was chosen for the preparation of the final nanoemulsions. In this case, the lower amount of surfactant could reduce the interfacial tension and increase the interfacial area, resulting in a stable dispersion. ${ }^{8}$

\section{Droplet size and polydispersity index}

Table 3 shows the physicochemical properties of the T802 formulation. Bluish transparent T802, with the droplet size of $16.52 \mathrm{~nm}$, was obtained. The polydispersity index showed that T802 had a narrow size distribution $(<0.1)$. Figure 2 shows very little increase in particle size and polydispersity after the T802 contact with the hydrocolloids. However, no significant effect was observed on droplet size before (T802 as a reference) and after the nanoemulsion was modified using gellan gum and xanthan gum. Gellan gum and xanthan gum are very soluble in water, which lead to the formation of the gel network in a continuous phase in the nanoemulsion even though the gel network increased the viscosity of nanoemulsions. ${ }^{17}$

The polydispersity of the T802 formulation was increased from 0.093 to $0.199,0.203$, and 0.332 after the nanoemulsions were modified with gellan gum, carrageenan, and xanthan gum, respectively. A high polydispersity system was observed when carrageenan and xanthan gum were used. Carrageenan and xanthan gum are polysaccharides, but possess very polar groups (sulfate and carboxyl groups, respectively). These hydrocolloids induced aggregation, as was indicated by an increase in mean particle size. Due to the high polydispersity of these samples, the nanoemulsions modified with carrageenan and xanthan gum (M2 and M3, in Table 2) were not chosen for further study. 


\section{Tween 80}

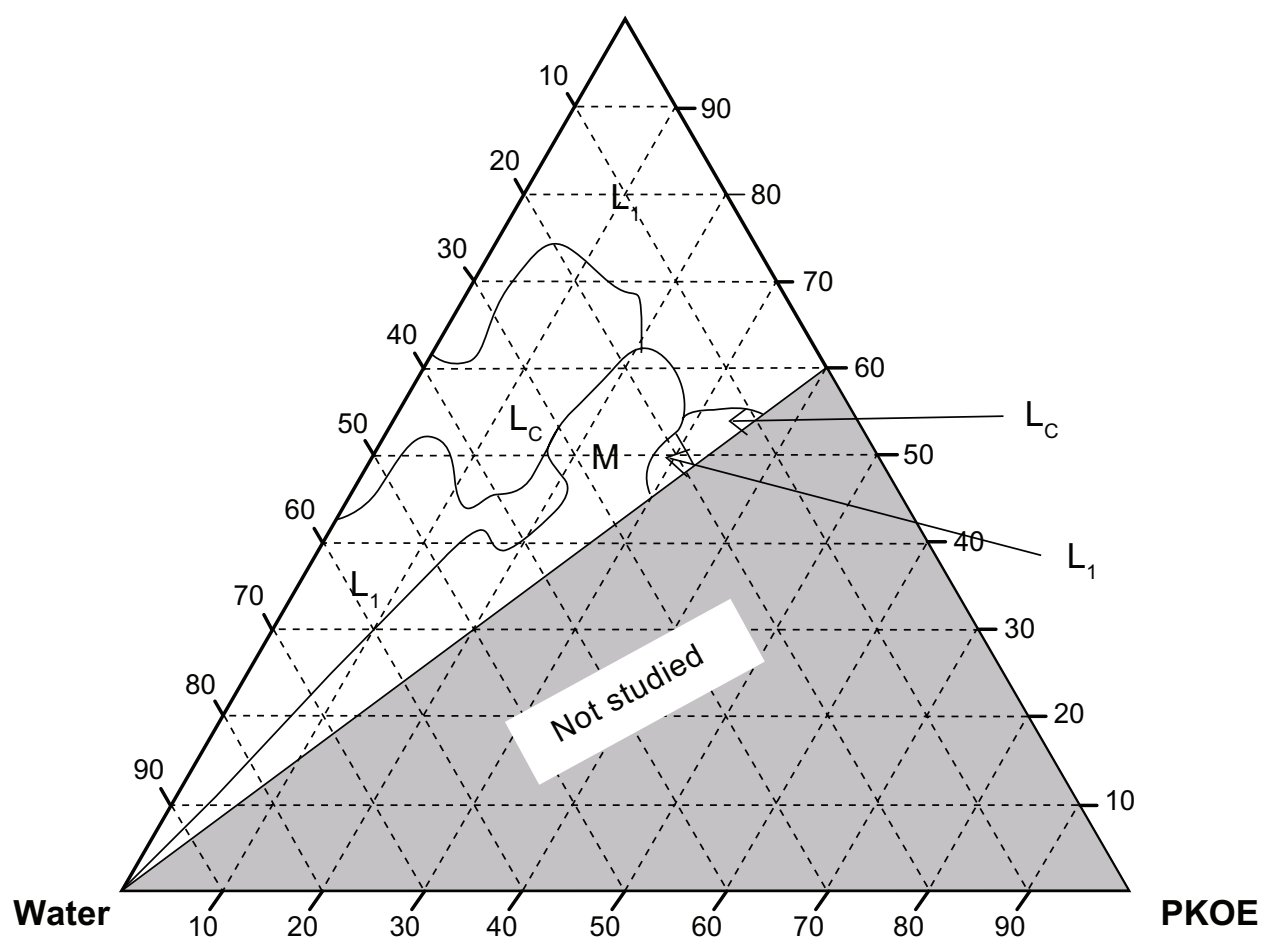

Figure I Ternary phase diagram of PKOE/Tween $80 /$ water system at $25^{\circ} \mathrm{C} \pm 1^{\circ} \mathrm{C}$.

Abbreviations: $L_{1}$, isotropic liquid region; Lc, liquid crystalline region; $M$, multiphase region; PKOE, palm kernel oil esters.

\section{Zeta potential}

Figure 3 shows the zeta potential distribution curve of initial nanoemulsion for sample T802. The zeta potential value for the T802 was $-11.0 \mathrm{mV}$. Figure 4 shows the zeta potential values of T802 (as reference) and the nanoemulsions modified with different hydrocolloids. When Formulation T802 was modified with hydrocolloids (gellan gum, carrageenan and xanthan gum), the zeta potential value increased to $-19.6 \mathrm{mV}$, $-13.9 \mathrm{mV}$, and $-41.9 \mathrm{mV}$, respectively. The possible interaction between the negative surface charge of the T802 and polar groups in the hydrocolloids (eg, carboxyl or sulfate group) could have increased the zeta potential of the system. It has previously been shown that the negatively charged carboxyl and sulfate groups in hydrocolloids are capable of increasing

Table 3 Physicochemical properties of the initial nanoemulsion formulation

\begin{tabular}{ll}
\hline & T802 \\
\hline Droplet size $(\mathrm{nm})$ & $16.52 \pm 0.0816$ \\
Polydispersity index & $0.0926 \pm 0.0176$ \\
Zeta potential $(\mathrm{mV})$ & $-1 \mathrm{l} .04 \pm 0.5595$ \\
Viscosity $(\mathrm{cP})$ & $\mathrm{I} 2$ \\
Appearance & Bluish transparent liquid \\
\hline
\end{tabular}

Abbreviation: T802, initial nanoemulsion. the negative charge at the surface of the nanoemulsion and changing the zeta potential values. ${ }^{18}$

\section{Rheology}

Figure 5 shows the viscosity versus shear rate for T802 and the nanoemulsion modified with gellan gum (M1). The viscosity decreased with increasing shear rate and reached a constant value at high shear rates. Shear thinning behavior that occurred in the modified nanoemulsion,

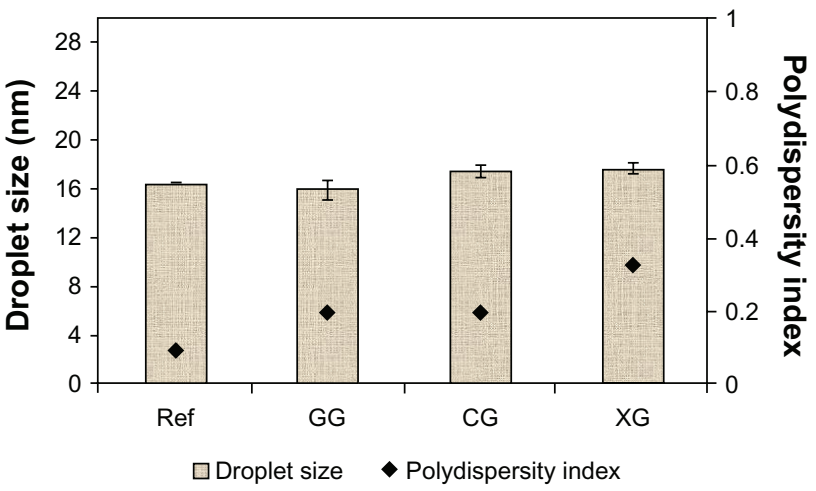

Figure 2 Droplet size and polydispersity index for the initial nanoemulsion (T802) and the modified nanoemulsion.

Note: Mean \pm SD, $\mathrm{n}=3$.

Abbreviations: Ref, reference; GG, gellan gum; CG, carrageenan; XG, xanthan gum; SD, standard deviation. 


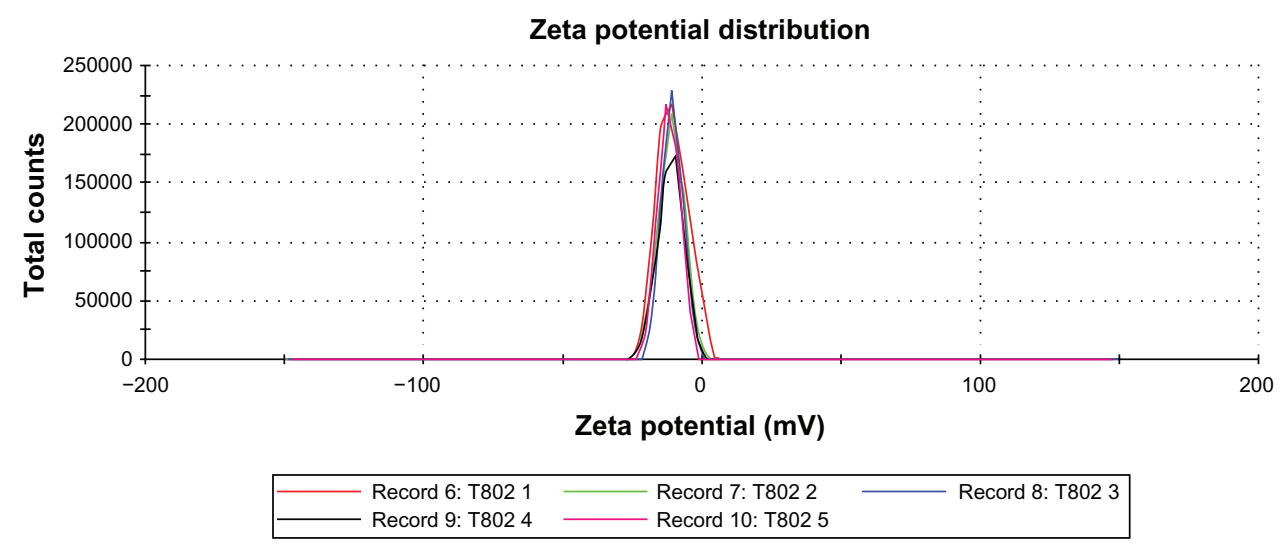

Figure 3 Zeta potential distributions for the nanoemulsion sample T802.

could be an indication of weak attractive forces between the emulsion droplets, which tend to disperse due to shear stress. The presence of high-molecular-weight hydrocolloids increased the resistance to flow, which in turn increased the apparent viscosity of the emulsion system. It also provided better long-term stability, probably arising from the immobilization of the emulsion droplets in a network (caused by a repulsive effect of available electrostatic charges on the molecules). ${ }^{19}$

\section{TEM imaging}

In order to observe the physical properties of the oil droplets in the nanoemulsion sample, TEM analysis was performed with negatively stained samples. Figure 6A shows the TEM images for the nanoemulsion sample T802. When T802 was used, the spherical shape of the nanoemulsion became more regular and smaller droplets were dominant. The droplet size range of 16-20 nm was obtained and revealed good size distribution. This droplet size was in agreement with the results

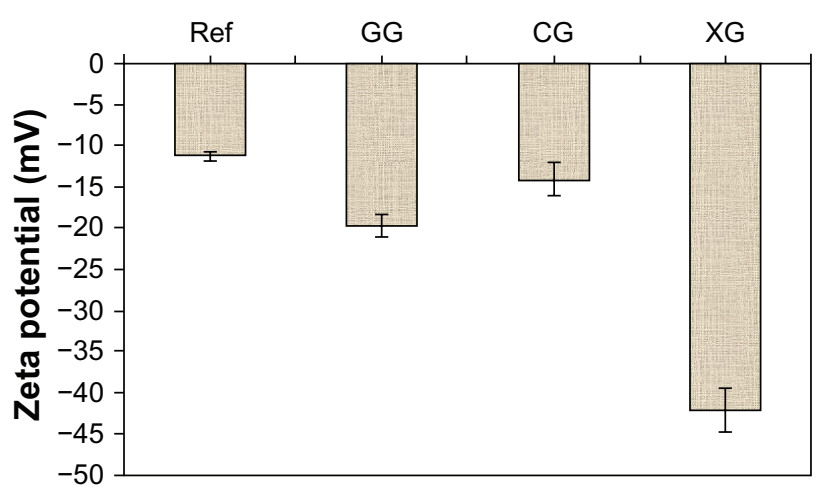

Figure 4 Zeta potential values for the initial nanoemulsion (T802) and the modified nanoemulsion.

Note: Mean \pm SD, $\mathrm{n}=3$.

Abbreviations: Ref, reference; GG, gellan gum; CG, carrageenan; XG, xanthan gum; $\mathrm{SD}$, standard deviation. obtained from the zetasizer (Malvern Instruments Ltd) and there was no evidence of ibuprofen precipitation in either the oil phase or the aqueous phase, at the concentration that was incorporated in the nanoemulsions.

Figure 6B shows the TEM image of T802 after being modified with hydrocolloid (M1). No droplets were detected and only the gel network was observed. Gellan gum swelled in aqueous water, resulting in an increase in viscosity of the nanoemulsion from the formation of a gel network of gellan gum in the aqueous phase. The increased viscosity of the nanoemulsion resulted in oily droplets that could not move freely in the hydrocolloid. Hence, the modified emulsions remained as the nanostructure of the emulsions within the three-dimensional gel network. ${ }^{20}$

\section{In vitro permeation studies}

The permeation ability of selected formulations was evaluated using in vitro permeation experiments. The calibration curves exhibited an excellent linearity over the concentration range of $5.2334-1011.8583 \mu \mathrm{g} / \mathrm{mL}$. The mean linear regression equation from three replicated calibration curves was

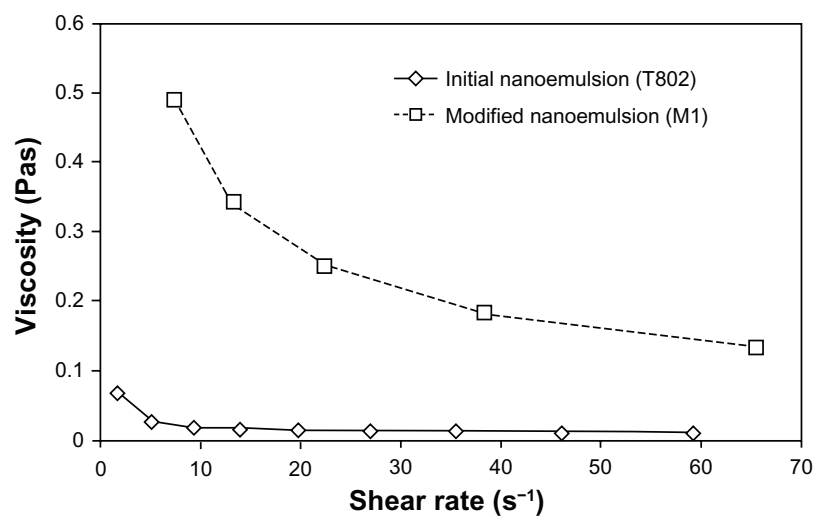

Figure 5 Viscosity versus shear rate for the initial and modified nanoemulsions. 

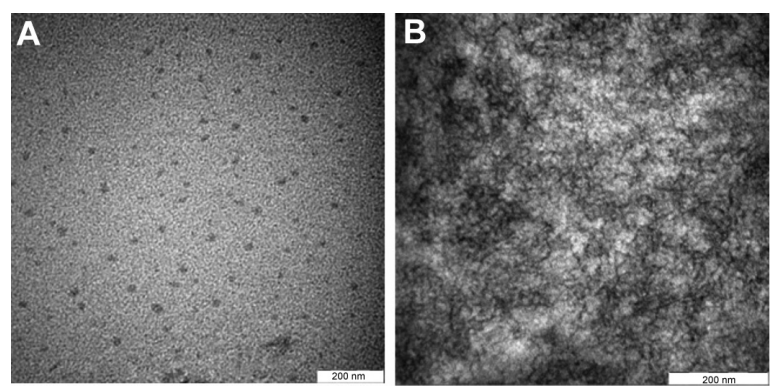

Figure 6 The TEM images of (A) the initial (T802), and (B) the modified (MI) nanoemulsions.

$y=2296.8 x+1586.4$ with a correlation coefficient of 1 (accuracy $>98 \%$ ). Table 4 shows the permeation parameters of T802 and M1. Figure 7 shows the permeation profiles of ibuprofen through rat skin from both nanoemulsions. A steady increase of ibuprofen released in the receptor compartment was observed over 1-8 hours of permeation. Statistical comparisons of the flux throughout M1 provided fluxes $\left(49.32 \pm 4.88 \mu \mathrm{g} \cdot \mathrm{cm}^{-2} \cdot \mathrm{h}^{-1}\right)(P<0.05)$ and $\mathrm{Kp}$ value $\left(55.4 \times 10^{-3} \mathrm{~cm} \cdot \mathrm{h}^{-1}\right)$ higher than those for T802 $\left(25.25 \pm 5.87 \mu \mathrm{g} \cdot \mathrm{cm}^{-2} \cdot \mathrm{h}^{-1}\right.$ and $12.6 \times 10^{-3} \mathrm{~cm} \cdot \mathrm{h}^{-1}$, respectively). M1 had the shortest lag time ( 0.686 hours), while T802 had the longest lag time (1.423 hours). The long lag time resulted in a decrease in accumulative amount of ibuprofen through the skin. The permeation profiles of nanoemulsions M1 followed Higuchi's model for drug release (Mt versus square root of $\mathrm{t}$ ), as the plot showed high linearity, with correlation coefficient $\left(\mathrm{R}^{2}\right)$ value of 0.9954 . A previous study ${ }^{21}$ comparing M1 with Nurofen ${ }^{\circledR} \%$ Gel (Reckitt Benckiser, Berkshire, UK), found
Table 4 The permeation parameters of the initial and modified nanoemulsion

\begin{tabular}{lllll}
\hline & $\begin{array}{l}\text { Flux at } \mathbf{8} \mathbf{h} \\
\left(\mathbf{J}, \boldsymbol{\mu g} \cdot \mathbf{c m}^{-2} \cdot \mathbf{h}^{-1}\right)\end{array}$ & $\begin{array}{l}\text { Permeated } \\
\text { amount at } \mathbf{8} \mathbf{h}(\%)\end{array}$ & $\begin{array}{l}\text { Kp } \\
\left(\mathbf{I} \mathbf{0}^{-3}, \mathbf{c m} / \mathbf{h}\right)\end{array}$ & $\mathbf{T}_{\mathbf{L}} \mathbf{( h )}$ \\
\hline T802 & $25.25 \pm 5.87$ & 6.5 & 12.6 & 1.423 \\
MI & $49.32 \pm 4.88$ & 28.4 & 55.4 & 0.686 \\
\hline
\end{tabular}

Note: Mean $\pm S D, n=3$.

Abbreviations: $\mathrm{Kp}$, permeability coefficient; $\mathrm{T}_{L}$, lag time; $\mathrm{T} 802$, initial nanoemulsion; MI, initial nanoemulsion modified with gellan gum; SD, standard deviation; $h$, hours.

the permeation rate of $\mathrm{M} 1$ to be 7.73 times higher than that of the marketed product. Nurofen 5\% Gel contains hydroxyethyl cellulose as a hydrocolloid gum.

The permeation results are in contrast to previous reports in various publications that claim increased penetration with increased viscosity. Surprisingly, it appears that the permeability of ibuprofen at 8 hours was 4.40 times higher with M1, when compared with T802. Theoretically, the rate of drug release may decrease, as the nanoemulsion transforms to a lamellar structure or an emulsion having a highly ordered nanostructure and increased viscosity. ${ }^{22}$ The addition of the hydrocolloid gum could be the main reason for the increased permeability of M1, which could in turn, have increased the thermodynamic activity of ibuprofen. Ibuprofen is readily soluble in oil. The addition of hydrocolloid increased the lipophilicity of the oil droplets hence, increased the thermodynamic activity, with consequent increase of the skin permeation rate. ${ }^{23}$

Although the interactions of nanoemulsions with skin depend on the electrical charge of the droplets, other factors, such as composition of the formulation, may also affect

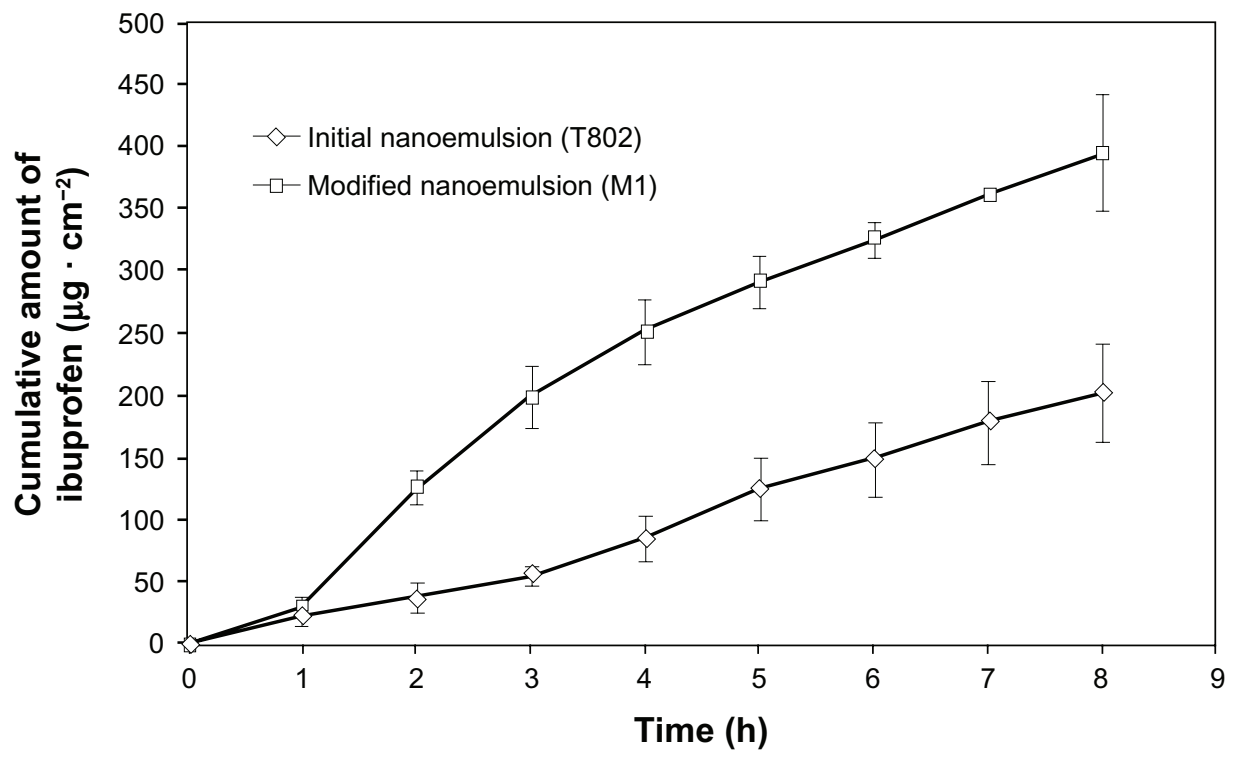

Figure 7 The permeation profiles of ibuprofen through Wistar rat skin. Note: Mean \pm standard deviation, $n=3$. 
the permeation. It is well known that the skin is negatively charged at neutral $\mathrm{pH} .{ }^{24}$ In the present study, the negatively charged nanoemulsions could have enhanced the permeation of ibuprofen through the skin. The composition of the nanoemulsion system (such as the PKOE and surfactant) could also have contributed to the enhancement of permeation.

\section{Conclusion}

The present study showed that when an initial PKOE nanoemulsion was modified with different hydrocolloids, there was no significant difference in droplet size observed, but there were significant differences in their polydispersities, zeta potentials, and flow behaviors. The permeability of ibuprofen at 8 hours was 4.40 times higher $(P<0.05)$ with the modified nanoemulsion (M1), when compared with the initial nanoemulsion (T802). The presence of a hydrocolloid in the nanoemulsions increased the permeation rate of ibuprofen, which made this suitable for topical drug delivery.

\section{Acknowledgments}

The authors gratefully acknowledge the financial support from the Ministry of Science, Technology and Innovation of Malaysia (MOSTI) under the National Biodiversity Division (NBD) project number 5487707, and National Science Fellowship (NSF) grant for the scholar, N Salim.

\section{Disclosure}

The authors report no conflicts of interest in this work.

\section{References}

1. Solans C, Izquierdo P, Nolla J, Azemar N, Garcia-Celma MJ. Nanoemulsions. Curr Opin Coll Interface Sci. 2005;10(3-4):102-110.

2. Tadros T, Izquierdo P, Esquena J, Solans C. Formation and stability of nano-emulsions. Adv Colloid Interface Sci. 2004;108-109: 303-318.

3. Shen Q, Wang Y, Zhang Y. Improvement of colchicine oral bioavailability by incorporating eugenol in the nanoemulsion as an oil excipient and enhancer. Int J Nanomedicine. 2011;6:1237-1243.

4. Araújo FA, Kelmann RG, Araújo BV, Finatto RB, Teixeira HF, Koester LS. Development and characterization of parenteral nanoemulsions containing thalidomide. Eur J Pharm Sci. 2011;42(3):238-245.

5. Hagigit T, Abdulrazik M, Valamanesh F, Behar-Cohen F, Benita S. Ocular antisense oligonucleotide delivery by cationic nanoemulsion for improved treatment of ocular neovascularization: an in-vivo study in rats and mice. J Control Release. 2012;160(2):225-231.

6. Abdulkarim MF, Abdullah GZ, Chitneni M, et al. Topical piroxicam in vitro release and in vivo anti-inflammatory and analgesic effects from palm oil esters-based nanocream. Int J Nanomedicine. 2010;5: 915-924.
7. Sonneville-Aubrun O, Simonnet JT, L'Alloret F. Nanoemulsions: a new vehicle for skincare products. Adv Colloid Interface Sci. 2004; 108-109:145-149.

8. Mason TG, Wilking JN, Meleson K, Chang CB, Graves SM. Nanoemulsions: formation, structure, and physical properties. $J$ Phys Condens Matter. 2006;18(41):635-666.

9. Mou D, Chen H, Du D, et al. Hydrogel-thickened nanoemulsion system for topical delivery of lipophilic drugs. Int J Pharm. 2008;353(1-2): 270-276.

10. Yano T, Nakagawa A, Tsuji M, Noda, K. Skin permeability of various non-steroidal anti-inflammatory drugs in man. Life Sci. 1986;39(12):1043-1050.

11. Chen H, Chang X, Du D, Li J, Xu H, Yang X. Microemulsion-based hydrogel formulation of ibuprofen for topical delivery. Int $J$ Pharm. 2006;315(1-2):52-58.

12. Rhee YS, Chang SY, Park CW, Chi SC, Park ES. Optimization of ibuprofen gel formulations using experimental design technique for enhanced transdermal penetration. Int J Pharm. 2008;364(1): $14-20$.

13. Gunawan ER, Basri M, Abdul Rahman MB, Salleh AB, Rahman RNZA. Study on response surface methodology (RSM) of lipase-catalyzed synthesis of palm-based wax ester. Enzyme and Microbial Technology. 2005;37(7):739-744.

14. Keng PS, Basri M, Zakaria MRS, et al. Newly synthesized palm esters for cosmetics industry. Ind Crops Prod. 2009;29(1):37-44.

15. Gunawan ER, Basri M, Rahman MBA, Rahman RNZA, Salleh AB. Lipase-catalyzed synthesis of palm-based wax esters. J Oleo Sci. 2004;53(1):471-477.

16. Maestro A, Solè I, González C, Solans C, Gutiérrez JM. Influence of the phase behavior on the properties of ionic nanoemulsions prepared by the phase inversion composition method. J Colloid Interface Sci. 2008;327(2):433-439.

17. Lapasin R, Grassi M, Coceani N. Effects of polymer addition on the rheology of o/w microemulsions. Rheol Acta. 2001;40(2):185-192.

18. Souto EB, Wissing SA, Barbosa CM, Müller RH. Evaluation of the physical stability of SLN and NLC before and after incorporation into hydrogel formulations. Eur J Pharm Biopharm. 2004;58(1): 83-90.

19. Dickinson D. Hydrocolloids as emulsifiers and emulsion stabilizers. Food Hydrocoll. 2009;23(6):1473-1482.

20. Chen H, Xiao L, Du D, Mou D, Xu H, Yang X. A facile construction strategy of stable lipid nanoparticles for drug delivery using a hydrogel-thickened microemulsion system. Nanotechnology [serial on the internet]. January 8, 2010; doi:10.1088/0957-4484/21/1/015101. http://iopscience.iop.org/0957-4484/21/1/015101/. Accessed July 29, 2012.

21. Abdullah GZ, Abdulkarim MF, Salman IM, et al. In vitro permeation and in vivo anti-inflammatory and analgesic properties of nanoscaled emulsions containing ibuprofen for topical delivery. Int J Nanomedicine. 2011;6:387-396.

22. Trotta M. Influence of phase transformation on indomethacin release from microemulsions. J Control Release. 1999;60(2-3):399-405.

23. Bialik W, Walters KA, Brain KR, Hadgraft J. Some factors affecting the in vitro penetration of ibuprofen through human skin. Int J Pharm. 1993;92(1-3):219-223.

24. Yilmaz E, Borchert HH. Design of a phytosphingosine-containing, positively-charged nanoemulsion as a colloidal carrier system for dermal application of ceramides. Eur J Pharm Biopharm. 2005;60(1): 91-98. 
International Journal of Nanomedicine

Dovepress

\section{Publish your work in this journal}

The International Journal of Nanomedicine is an international, peerreviewed journal focusing on the application of nanotechnology in diagnostics, therapeutics, and drug delivery systems throughou the biomedical field. This journal is indexed on PubMed Central, MedLine, CAS, SciSearch ${ }^{\circledR}$, Current Contents ${ }^{\circledR} /$ Clinical Medicine,
Journal Citation Reports/Science Edition, EMBase, Scopus and the Elsevier Bibliographic databases. The manuscript management system is completely online and includes a very quick and fair peer-review system, which is all easy to use. Visit http://www.dovepress.com/ testimonials.php to read real quotes from published authors.

Submit your manuscript here: http://www.dovepress.com/international-journal-of-nanomedicine-journal 